HJIMB Vol 2, No. 1 2020, pp: 90-94

https://doi.org/10.30606/hiimb

HIRARKI

Jurnal Ilmiah Manajemen dan Bisnis

http://iournal.upp.ac.id/index.php/Hirarki

\title{
PENGARUH KEPEMIMPINAN TRANSFORMASIONAL, TRANSAKSIONAL DAN MOTIVASI KERJA TERHADAP KINERJA KARYAWAN DENGAN KOMITMEN ORGANISASI SEBAGAI VARIABEL INTERVENING DI UNIVERSITAS ‘AISYIYAH YOGYAKARTA.
}

Armansyah

Fakultas Ekonomi, Program Studi Manajemen, STIE Pembangunan Tanjungpinang

Info Artikel

Sejarah Artikel:

Diterima 09 Januari 2020

Disetujui 15 Januari 2020

Dipublikasikan

29 Fabruari 2020

\section{Keywords:}

Kepemimpinan

Transformasional,

Kepemimpinan

Transaksional, Motivasi

Kerja, Kinerja Karyawan

dan Komitmen Organisasi

\begin{abstract}
Abstrak
Pada penelitian ini menggunakan teknik pengambilan sampel menggunakan metode sensus. Metode sensus adalah teknik penentuan sampel bila semua anggota populasi digunakan sebagai sampel. Alat analisis yang digunakan adalah Analisis Regresi Linier Berganda serta analisis jalur (Path Analysis). Hasil penelitian menunjukkan bahwa Kepemimpinan transformasional, kepemimpinan transaksional serta motivasi kerja secara parsial dan simultan mempunyai pengaruh signifikan terhadap Kinerja karyawan. Kepemimpinan transformasional, kepemimpinan transaksional serta motivasi kerja secara parsial dan simultan mempunyai pengaruh signifikan terhadap Komitmen Organisasi. Komitmen Organisasi secara parsial mempunyai pengaruh signifikan terhadap Kinerja karyawan. Pengaruh secara langsung kepemimpinan transformasional, kepemimpinan transaksional serta motivasi kerja terhadap kinerja karyawan melalui komitmen organisasi memiliki pengaruh lebih besar daripada pengaruh tidak langsung kepemimpinan transformasional, kepemimpinan transaksional serta motivasi kerja terhadap kinerja karyawan melalui komitmen organisasi.
\end{abstract}

\section{EFFECT OF TRANSFORMATIONAL LEADERSHIP, TRANSACTIONAL AND WORK MOTIVATION ON EMPLOYEE PERFORMANCE WITH ORGANIZATIONAL COMMITMENT AS AN INTERVENING VARIABLE IN THE UNIVERSITY 'AISYIYAH YOGYAKARTA}

Alamat korespondensi :

STIE Pembangunan Tanjungpinang

Manchah494@gmail.com

\begin{abstract}
In this study using a sampling technique using the census method. The census method is a sampling technique when all members of the population are used as samples. The analytical tool used is Multiple Linear Regression Analysis and Path Analysis. The results showed that transformational leadership, transactional leadership and work motivation partially and simultaneously had a significant effect on employee performance. Transformational leadership, transactional leadership and work motivation partially and simultaneously have a significant influence on Organizational Commitment. Organizational Commitment partially has a significant influence on employee performance. The direct effect of transformational leadership, transactional leadership and work motivation on employee performance through organizational commitment has a greater influence than the indirect effect of transformational leadership, transactional leadership and work motivation on employee performance through organizational commitment




\section{PENDAHULUAN}

Dalam suatu organisasi atau perusahaan senantiasa berusaha meningkatkan efektifitas organisasi untuk dapat bertahan hidup dan berkompetisi dalam menghadapi perubahan lingkungan yang cepat. Untuk itu dibutuhkan adanya suatu kepemimpinan yang dapat membawa organisasi kepada tujuan yang telah ditentukan. Leadership atau kepemimpinan merupakan kemampuan untuk mempengaruhi orang atau kelompok orang ke arah pencapaian suatu tujuan, dan di dalam dunia yang dinamis seperti saat ini, organisasi memerlukan kepemimpinan-kepemimpinan yang mampu menantang status quo, untuk menciptakan visi misi masa depan dan untuk menginspirasikan para anggota organisasi untuk memiliki keinginan mencapai visi misi tersebut (Robbins, 2010:129), mungkin tidak seorang pun dapat membantah pentingnya leadership bagi keberhasilan suatu organisasi. Pemimpin dapat mempengaruhi perilaku para bawahan melalui gaya atau pendekatan yang digunakan untuk mengelola organisasi. Ada dua gaya kepemimpinan yang menjadi perhatian utama para pakar organisasi, yaitu transactional dan transformational leadership (Benyamin and Flyinn, 2006:216). Transactional merupakan suatu dinamika pertukaran antara pimpinan dan bawahan dimana pimpinan menetapkan sasaran-sasaran khusus, memonitor perkembangan, dan mengidentifikasi rewards atau penghargaan yang dapat diharapkan oleh bawahan bilamana sasaran dapat dicapai. Sedangkan Transformational leadership menyangkut bagaimana mendorong orang lain untuk berkembang dan menghasilkan kinerja melebihi standar yang diharapkan (Bass, 1990).Sedangkan kepemimpinan transformasional adalah model pemimpin yang mengkomunikasikan visi dan tujuan organisasi secara jelas sehingga bawahan dapat mengidentifikasi dan cenderung menimbulkan pengaruh yang kuat pada pengikut, memberikan motivasi pada bawahannya serta merangsang kreativitas untuk bekerja lebih baik demi tercapainya tujuan organisasi. Para pengikut seorang pemimpin transformasional merasa adanya kepercayaan, kekaguman, kesetiaan, dan hormat terhadap pemimpin tersebut, dan mereka termotivasi untuk melakukan lebih daripada yang awalnya diharapkan terhadap mereka (Bass, 1990). Salah satu faktor perilaku penting bagi efektivitas organisasi yang mempengaruhi perilaku para karyawan antara lain adalah komitmen mereka terhadap organisasi atau organizational commitment (OC). Komitmen dalam organisasi menunjukkan hasrat karyawan terhadap perusahaan untuk tetap tinggal dan bekerja serta mengabdikan diri bagi perusahaan.

Kinerja seorang karyawan dapat dilihat dari seberapa besar kontribusi karyawan terhadap perusahaan. Agar dapat mengetahui seberapa besar kontribusi yang akan dilakukan karyawan, salah satunya dengan menggunakan cara penilaian kinerja karyawan. Jackson (2002:78), menyatakan bahwa kinerja pada dasarnya adalah apa yang dilakukan atau tidak dilakukan pegawai.

Penelitian ini mengambil obyek penelitian pada Universitas 'Aisyiyah Yogyakarta. 'Aisyiyah dalam menyelenggarakan pendidikan dimulai dari taman kanak-kanak sampai tingkat pendidikan tinggi.

\section{METODE PENELITIAN}

Obyek dalam penelitian ini adalah karyawan Universitas 'Aisyiyah Yogyakarta sebanyak 50 karyawan yang dijadikan sebagai populasi dengan teknik 
pengambilan sampel menggunakan metode sensus. Metode sensus adalah teknik penentuan sampel bila semua anggota populasi digunakan sebagai sampel.

Sumber data dalam penelitian ini terdiri data primer dan data sekunder. Data primer, yaitu data yang diperoleh langsung dari objek penelitian yaitu karyawan Universitas 'Aisyiyah Yogyakarta. Sementara data sekunder, yaitu data yang berkaitan dengan keberadaan Universitas 'Aisyiyah Yogyakarta. Jenis data dalam penelitian ini ada dua data kuantitatif dan kualitatif. Data Kuantitatif yaitu data berupa angka angka yang berhubungan dengan penelitian yang penulis teliti dan kaitkan dengan teori teori yang ada. Sedangkan data kualitatif yaitu data data selain angka angka yang diperoleh melalui angket atau kuesioner disusun dalam bentuk tabel tabel dan presentasi, kemudian aspek aspek yang terdapat dalam table tersebut dibandingkan atau diintrepetasikan sehingga diperoleh pembahasan yang lebih luas dari tabel tersebut. Yang diperoleh dari Universitas 'Aisyiyah Yogyakarta yang dijadikan data pendukung dalam penelitian penulis.

Teknik pengumpulan data nya adalah Kuesioner, dan Studi Pustaka. Teknik analisi data dalam penelitian ini menggunakan Analisis Regresi Berganda serta analisis jalur (Path Analysis). Analisi regresi linier berganda digunakan untuk mengetahui ada tidaknya dan atau besar kecilnya pengaruh variabel bebas terhadap variabel terikat.

\section{HASIL DAN PEMBAHASAN}

Analisis Regresi Tahap I Tabel .1 Uji Pengaruh Individual Uji t

\begin{tabular}{|c|c|c|c|c|c|c|}
\hline \multirow[t]{2}{*}{ Mode } & & \multicolumn{2}{|c|}{$\begin{array}{c}\text { Unstandardized } \\
\text { Coefficients } \\
\end{array}$} & \multirow{2}{*}{$\begin{array}{c}\begin{array}{c}\text { Standardized } \\
\text { Coefficients }\end{array} \\
\text { Beta } \\
\end{array}$} & \multirow[t]{2}{*}{$t$} & \multirow[t]{2}{*}{ Sig. } \\
\hline & & $B$ & Std. Error & & & \\
\hline \multirow{4}{*}{1} & (Constant) & .544 & .288 & & 1.888 & .065 \\
\hline & KepemimpinanTransformasional & .616 & .128 & .561 & 4.828 & .000 \\
\hline & KepemimpinanTransaksional & .333 & .074 & .448 & 4.500 & .000 \\
\hline & MotivasiKerja & .119 & .056 & .117 & 2.111 & .037 \\
\hline
\end{tabular}

Berdasarkan Tabel model regresi berganda dihasilkan persamaan Kinerja

$Y=0.544+0.616 X_{1}+0.333 X_{2}+0.119 X_{3}$

Hasil Uji Pengaruh Individual (Uji

t) adalah sebagai berikut:

Kepemimpinan transformasional secara parsial mempunyai pengaruh signifikan terhadap Kinerja karyawan dengan nilai signifikansi $t$ statistic sebesar 0.000 .

Kepemimpinan transaksional secara parsial mempunyai pengaruh signifikan terhadap Kinerja karyawan dengan nilai signifikansi $t$ statistic sebesar 0.000 .

Motivasi kerja secara parsial mempunyai pengaruh signifikan terhadap Kinerja karyawan dengan nilai signifikansi $t$ statistic sebesar 0.037 .

Uji F dan Koefisien Determinasi $\left(\mathbf{R}^{2}\right)$ Tabel.2 Pengujian Hipotesis secara Simultan

\begin{tabular}{|c|c|c|c|c|c|c|}
\hline \multicolumn{7}{|c|}{$\mathrm{ANOVA}^{\mathrm{B}}$} \\
\hline Mod & & Sum of Squares & $D f$ & Mean Square & $\mathrm{F}$ & Sig. \\
\hline \multirow{3}{*}{1} & Regression & 24.201 & 3 & 8.067 & 49.658 & $.000^{\circ}$ \\
\hline & Residual & 7.473 & 46 & .162 & & \\
\hline & Total & 31.673 & 49 & & & \\
\hline
\end{tabular}

Kepemimpinantransformasional,transaksi onal dan motivasi kerja secara simultan mempunyai pengaruh signifikan terhadap Kinerja karyawan dengan nilai signifikansi $F$ statistic sebesar 0.000 . 
Koefisien Determinasi

Model Summary ${ }^{\circ}$

\begin{tabular}{|l|r|r|r|r|}
\hline Model & \multicolumn{1}{|l|}{$R$} & R Square & \multicolumn{1}{c|}{$\begin{array}{c}\text { Adjusted } R \\
\text { Square }\end{array}$} & $\begin{array}{c}\text { Std. Error of the } \\
\text { Estimate }\end{array}$ \\
\hline 1 & $.874^{\mathrm{a}}$ & .764 & .749 & .40305 \\
\hline
\end{tabular}

a.Predictors: (Constant), MotivasiKerja, KepemimpinanTransaksional,

KepemimpinanTransformasional

b. DependentVariable:KinerjaKaryawan

\section{Analisis Regresi Tahap II}

Tabel .3 Uji Pengaruh Individual Uji t

\begin{tabular}{|c|c|c|c|c|c|c|}
\hline \multirow[t]{2}{*}{ Mode } & & \multicolumn{2}{|c|}{$\begin{array}{c}\text { Unstandardized } \\
\text { Coefficients }\end{array}$} & \multirow{2}{*}{\begin{tabular}{|c|}
$\begin{array}{c}\text { Standardized } \\
\text { Coefficients }\end{array}$ \\
Beta \\
\end{tabular}} & \multirow[t]{2}{*}{$\mathrm{t}$} & \multirow[t]{2}{*}{ Sig. } \\
\hline & & $B$ & Std. Error & & & \\
\hline \multirow{4}{*}{1} & (Constant) & 6.137 & .312 & & 19.690 & .000 \\
\hline & KepemimpinanTransformasional & .407 & .138 & .370 & 2.951 & .005 \\
\hline & KepemimpinanTransaksional & .271 & .080 & .364 & 3.385 & .001 \\
\hline & MotivasiKerja & .219 & .107 & .230 & 2.051 & .046 \\
\hline
\end{tabular}

a. DependentVariable: Komitmen

Berdasarkan Tabel model regresi berganda di dapatkan hasil persamaan regresi linear berganda

\section{$Z=6.137+0.407 X_{1}+0.271 X_{2}+0.219 X_{3}$}

Hasil Uji Pengaruh Individual (Uji

t) adalah sebagai berikut:

Kepemimpinan transformasional secara parsial mempunyai pengaruh signifikan terhadap Komitmen organisasi dengan nilai signifikansi $t$ statistic sebesar 0.005 .

Kepemimpinan transaksional secara parsial mempunyai pengaruh signifikan terhadap Komitmen organisasi dengan nilai signifikansi $t$ statistic sebesar 0.001 .

Motivasi kerja secara parsial mempunyai pengaruh signifikan terhadap Komitmen organisasi dengan nilai signifikansi $t$ statistic sebesar 0.046 .
Uji F dan Koefisien Determinasi $\left(\mathbf{R}^{2}\right)$ Tabel. 4 Pengujian Hipotesis secara Simultan

\begin{tabular}{|c|c|c|c|c|c|c|}
\hline \multicolumn{7}{|c|}{ ANOVA $^{3}$} \\
\hline Mo & & Sum of Squares & Df & Mean Square & $\mathrm{F}$ & Sig. \\
\hline \multirow{3}{*}{1} & Regression & 23.022 & 3 & 7.674 & 40.407 & $.000^{\circ}$ \\
\hline & Residual & 8.736 & 46 & .190 & & \\
\hline & Total & 31.758 & 49 & & & \\
\hline
\end{tabular}

a. DependentVariable:Komitmen

b. Predictors: (Constant), MotivasiKerja, KepemimpinanTransaksional, Kepemimpinani|ransformasional

KepemimpinanTransformasiona, transaksional dan motivasi kerja secara simultan mempunyai pengaruh signifikan terhadap Komitmen organisasi dengan nilai signifikansi $F$ statistic sebesar 0.000 .

Tabel Koefisien Determinasi Model Summary ${ }^{\circ}$

\begin{tabular}{|l|r|r|r|r|}
\hline Model & \multicolumn{1}{|c|}{$R$} & RSquare & \multicolumn{1}{c|}{$\begin{array}{c}\text { Adjusted } R \\
\text { Square }\end{array}$} & $\begin{array}{c}\text { Std. Error of the } \\
\text { Estimate }\end{array}$ \\
\hline 1 & $.851^{3}$ & .725 & .707 & .43579 \\
\hline
\end{tabular}

a. Predictors: (Constant), MotivasiKerja, KepemimpinanTransaksional,

KepemimpinanTransformasional

b.DependentVariable: Komitmen

\section{Analisis Regresi Tahap III}

Tabel. 5 Uji Pengaruh Individual Uji t

\begin{tabular}{|c|c|c|c|c|c|c|}
\hline & & & Coetric & & & \\
\hline \multirow{2}{*}{\multicolumn{2}{|c|}{ Model }} & \multicolumn{2}{|c|}{ Unstandarorized Coefficients } & \multirow{2}{*}{$\begin{array}{c}\text { Standardized } \\
\text { Coefficients } \\
\text { Beta }\end{array}$} & \multirow[t]{2}{*}{$t$} & \multirow[t]{2}{*}{ Sig. } \\
\hline & & Bisnis & Sto. Error & & & \\
\hline & (Constant) & 6.246 & .232 & & 26.878 & .000 \\
\hline & Komitmen & .869 & .071 & .870 & 12.206 & .000 \\
\hline
\end{tabular}

a. DependentVariable: Kinerjakaryawan

Berdasarkan Tabel model regresi sederhana untuk kinerja karyawan atas faktor-faktor yang mempengaruhi yaitu Komitmen Organisasi sebagai berikut

\section{Kinerja $=6.246+0.869 Z$}

Komitmen organisasi secara parsial mempunyai pengaruh signifikan terhadap Kinerja karyawan dengan nilai signifikansi $t$ statistic sebesar 0.000 . 


\section{Analisis Pengaruh Total}

Penelitian menggunakan analisis statistik yaitu analisis jalur (Path Analysis). Analisis ini digunakan untuk menguji pengaruh variable intervening $\left(\mathrm{Y}_{1}\right)$ dimana penggunaan analisis regresi untuk menaksir hubungan kausalitas antar variable (model casual).

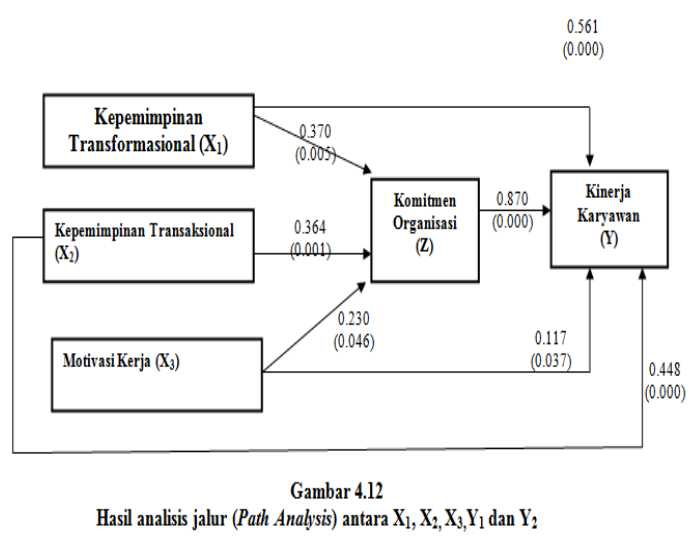

Sumber : Data primer diolah, 2016

Berdasarkan Gambar diatas, maka dapat dijelaskan pengaruh langsung dan tidak langsung sebagai berikut:

Pengaruh secara langsung kepemimpinan transformasional terhadap kinerja karyawan melalui komitmen organisasi memiliki pengaruh lebih besar daripada pengaruh tidak langsung kepemimpinan transformasional terhadap kinerja karyawan melalui komitmen organisasi.

Pengaruh secara langsung kepemimpinan transaksional terhadap kinerja karyawan melalui komitmen organisasi memiliki pengaruh lebih besar daripada pengaruh tidak langsung kepemimpinan transaksional terhadap kinerja karyawan melalui komitmen organisasi.

Pengaruh secara langsung motivasi merja terhadap kinerja karyawan melalui komitmen organisasi memiliki pengaruh lebih kecil daripada pengaruh tidak langsung motivasi kerja terhadap kinerja karyawan melalui komitmen organisasi

\section{KESIMPULAN}

Berdasarkan hasil analisis dan pembahasan tentang "Pengaruh Kepemimpinan Transformasional, Transaksional dan Motivasi Kerja terhadap Kinerja Karyawan dengan Komitmen Organisasi sebagai Variabel Intervening di Universitas "Aisyiyah Yogyakarta" dapat ditarik kesimpulan Berdasarkan hasil analisis:

KepemimpinanTransformasional secara parsial mempunyai pengaruh signifikan terhadap Kinerja karyawan dengan nilai signifikansi $t$ statistic sebesar $\quad 0.000$. Kepemimpinan Transaksional secara parsial mempunyai pengaruh signifikan terhadap Kinerja karyawan dengan nilai signifikansi $t$ statistic sebesar 0.000. Motivasi Kerja secara parsial mempunyai pengaruh signifikan terhadap Kinerja karyawan dengan nilai signifikansi $t$ statistic sebesar 0.037 .

KepemimpinanTransformasional, Kepemimpinan Transaksional dan Motivasi Kerja secara simultan mempunyai pengaruh signifikan terhadap Kinerja karyawan dengan nilai signifikansi $F$ statistic sebesar 0.000 .

KepemimpinanTransformasional secara parsial mempunyai pengaruh signifikan terhadap Komitmen Organisasi dengan nilai signifikansi $t$ statistic sebesar $\quad 0.005$. Kepemimpinan Transaksional secara parsial mempunyai pengaruh signifikan terhadap Komitmen Organisasi dengan nilai signifikansi $t$ statistic sebesar 0.001. Motivasi Kerja secara parsial mempunyai pengaruh signifikan terhadap Komitmen Organisasi dengan nilai signifikansi $t$ statistic sebesar 0.046 .

KepemimpinanTransformasional,Kepemi mpinan Transaksional dan Motivasi Kerja 
secara simultan mempunyai pengaruh signifikan terhadap Komitmen Organisasi dengan nilai signifikansi $F$ statistic sebesar 0.000. Komitmen Organisasi secara parsial mempunyai pengaruh signifikan terhadap Kinerja karyawan dengan nilai signifikansi $t$ statistic sebesar 0.000 .

Pengaruh secara langsung Kepemimpinan Transformasional terhadap kinerja karyawan melalui komitmen organisasi memiliki pengaruh lebih besar daripada pengaruh tidak langsung Kepemimpinan Transformasional terhadap kinerja karyawan melalui komitmen organisasi. Pengaruh secara langsung Kepemimpinan Transaksional terhadap kinerja karyawan melalui komitmen organisasi memiliki pengaruh lebih besar daripada pengaruh tidak langsung Kepemimpinan Transaksional terhadap kinerja karyawan melalui komitmen organisasi. Pengaruh secara langsung Motivasi Kerja terhadap kinerja karyawan melalui komitmen organisasi memiliki pengaruh lebih kecil daripada pengaruh tidak langsung Motivasi Kerja terhadap kinerja karyawan melalui komitmen organisasi.

\section{DAFTAR PUSTAKA}

Bass, B.M. 1985. Leadership and Performance Beyond Expectations. The Free Press

Bass, B.M. 1990. Bass and Stogdill's Hand Book of Leadership. New York: Free Press.

Bass, B.M. and Avolio, B.J. 1997. Full Range Leadership Development: Manual for The Multifactor Leadership Questionnaire. Redwood City: Mind Garden Inc
Dessler, Gary. 2006. Manajemen Sumber Daya Manusia Edisi Kesepuluh Jilid 1: Terj. Jakarta: Indeks.

Italiani, F.A. 2013. Pengaruh Gaya Kepemimpinan Transformasional dan Transaksional terhadap Kinerja Pegawai Departemen SDM PT. Semen Gresik (Persero) TBK. Jurnal Ilmu Manajemen. Volume 1 Nomor 2 Maret. Fakultas Ekonomi, Universitas Negeri Surabaya.

Mathis, dan Jackson, 2002, Manajemen Sumber Daya Manusia, Edisi pertama, Cetakan Pertama, Yogyakarta: Salemba Empat

Puspasari, M.A.W. 2013. Pengaruh Motivasi Dan Budaya Organisasi Terhadap Komitmen Organisasi dan Kinerja Karyawan. Jurnal Tesis. Program Studi Magister Manajemen. Yogyakarta. Universitas Atma Jaya

Robbins, Stephen P. 2006. Perilaku Organisasi, PT Indeks, Kelompok Gramedia, Jakarta.

Robbins, Stephen P. Dan Coulter, Mary. 2010. Manajemen Edisi Kesepuluh. Jakarta: Penerbit Erlangga.

Sopiah. 2008. Perilaku Organisasi. Yogyakarta: Penerbit Andi.

Sugiyono. 2007. Statistika Untuk Penelitian. Bandung: Alfabeta 